\title{
Long term COVID-19 complications in inpatients and outpatients: a one-year follow up cohort study
}

\author{
Michele Davide Maria Lombardo ${ }^{1 *}$, Andrea Foppiani $^{2 *}$, Giuseppe Michele Peretti ${ }^{3,4}$, Laura \\ Mangiavini $^{3,4}$, Alberto Battezzati ${ }^{2}$, Simona Bertoli ${ }^{2,5}$, Filippo Martinelli Boneschi ${ }^{6,7}$, Gian \\ Vincenzo Zuccotti ${ }^{8,9}$
}

\begin{abstract}
${ }^{1}$ Residency program in Orthopedic and Traumatology, University of Milan, Milan, Italy ${ }^{2}$ International Center for the Assessment of Nutritional Status, Department of Food Environmental and Nutritional Sciences, University of Milan, Milan, Italy.

${ }^{3}$ Department of Biomedical Sciences for Health, University of Milan, Milan, Italy

${ }^{4}$ IRCCS Istituto Ortopedico Galeazzi, 20161, Milan, Italy

${ }^{5}$ International Center for the Assessment of Nutritional Status, Department of Food Environmental and Nutritional Sciences, University of Milan, Milan, Italy. 6 IRCCS Fondazione Ca' Granda Ospedale Maggiore Policlinico, Neurology Unit, Milan, Italy. Via Francesco Sforza 35, 20122

7 Dino Ferrari Center, Department of Pathophysiology and Transplantation, University of Milan, Milan, Italy. Via Francesco Sforza 35, 20122

8 Department of Biomedical and Clinical Sciences "L. Sacco", Pediatric Clinical Research Center "Romeo and Enrica Invernizzi", University of Milan, Milan, Italy

${ }^{9}$ Department of Pediatrics, Children's Hospital Vittore Buzzi, University of Milan, Milan, Italy

* These authors have contributed equally to this manuscript.
\end{abstract}

Corresponding author: Gianvincenzo Zuccotti, gianvincenzo.zuccotti@unimi.it, Children’s Hospital "Vittore Buzzi”, Via Lodovico Castelvetro, 32, 20154 Milano MI, Italy

Alternate Author: Andrea Foppiani, andrea.foppiani@unimi.it, International Center for the Assessment of Nutritional Status, Department of Food Environmental and Nutritional Sciences, University of Milan, Milan, Italy. Phone number: + 393387178752

(C) The Author(s) 2021. Published by Oxford University Press on behalf of Infectious Diseases Society of America.

This is an Open Access article distributed under the terms of the Creative Commons AttributionNonCommercial-NoDerivs licence (http://creativecommons.org/licenses/by-nc-nd/4.0/), which permits non-commercial reproduction and distribution of the work, in any medium, provided the original work is not altered or transformed in any way, and that the work is properly cited. For commercial re-use, please contact journals.permissions@oup.com 


\section{Summary of the article's main point:}

One year after SARS-CoV-2 infection, most patients (81\%) presented at least one symptom with the most prevalent being fatigue and weakness (52\%), muscle and joint pain (48\%), sleep disorders $(47 \%)$, neurological and cognitive impairment (36\%), and respiratory disorders (36\%). 


\section{Abstract}

\section{Background}

As the coronavirus pandemic spreads, more and more people are infected with SARS-CoV-2. The short- and medium-term effects of the infection have been described, but the description of the long-term sequelae is lacking in the literature.

\section{Methods}

Patients healed from Covid-19 from February 2020 to May 2020 were considered for inclusion in this study, regardless of the severity of the disease during the acute phase. Eligible patients were consecutively contacted and a semi-structured interview was administered between February and March 2021 by trained medical staff.

\section{Results}

303 patients were eligible and accepted to participate in the study and were enrolled. Most patients $(81 \%)$ reported at least one symptom of those surveyed, and the most prevalent symptoms related to fatigue (52\%), pain (48\%) and sleep disorders (47\%). Sensory alterations were present in $28 \%$ of surveyed patients, but in most of these cases $(74 \%$ of those affected by sensory alterations or $20 \%$ of the overall sample) symptoms reported were either anosmia or dysgeusia. Higher prevalence was generally observed with increasing age, although the most relevant differences were observed when comparing young vs middle-aged adults. 


\section{Conclusion}

At 12-months after acute infection, COVID-19 survivors were still suffering of symptoms identified at shorter follow-up including fatigue, pain and sleep disorders among the most frequent. A more severe impairment in the acute phase did not seem to predict more severe complications.

Keywords: Covid-19, Long Covid, Covid sequelae, Covid pandemic 


\section{Introduction}

During the second year of coronavirus disease 19 (COVID-19) pandemic, the severe acute respiratory syndrome coronavirus 2 (SARS-CoV-2) continues to spread and affect more people worldwide. While the development and approval of the first COVID-19 vaccines may provide a way to end the pandemic, as of March 2021 more than 120 million people have been diagnosed and certainly more have been infected. ${ }^{1}$ The first evidence of long-term COVID-19 complications have recently surfaced, and in the future may represent one of the most significant global disease burdens.

Huang and colleagues described the consequences of COVID-19 six months after symptoms onset in patients who have been hospitalized during the acute phase of the disease. They show that most patients (76\%) are symptomatic to some degree, with the most frequently reported symptoms being fatigue and muscle weakness (63\%), sleep difficulties (26\%) and anxiety (23\%). ${ }^{2}$ Logue and colleagues also highlighted SARS-CoV2 effects with a median follow-up of 169 days. $^{3}$ They reported fatigue (14\%), loss of smell and taste (14\%) and brain fog (2\%), defined as being slightly less wakeful or aware than normal, as the most frequent symptoms. Graham and colleagues researched at 5-months follow-up long-term COVID-related neurological manifestations which were brain fog (81\%), headache (68\%), numbness/tingling (60\%), dysgeusia (59\%), anosmia (55\%), and myalgia (55\%). Moreover, in this study $85 \%$ of patients also experienced fatigue. ${ }^{4}$

While first evidence focuses on patients discharged from hospital, many diagnosed patients were never admitted into hospitals. During the first phase of the pandemic in Italy between February and May 2020, the epidemic has mostly affected the urban areas of the north of the country. ${ }^{5}$ These areas were unprepared for outbreak management; 
many patients required hospitalization, and, in a short time, hospitals reached full capacity, leading to early discharge of apparently stable patients and home surveillance of those who could not be admitted. For this reason, the Operations Center for Discharged Patients (Centrale Operativa Dimessi, COD19) was created as an active home surveillance system. ${ }^{6}$

With the emerging evidence of long-term sequelae of COVID-19, COD19 started a oneyear follow-up of patients originally monitored during the first Italian phase of the pandemic. The purpose of this study is to report the clinical consequences in the population affected by COVID-19, both inpatients and outpatients, 12 months after the recovery from the acute illness.

\section{Methods}

\section{Study design and patient's selection}

This study was part of a large cohort study of COVID+ patients at the COD19 operations center. Patients monitored from February 2020 to May 2020 were considered for inclusion in this study, regardless of the severity of the disease during the acute phase. We included all patients with a confirmed diagnosis of COVID-19, performed by molecular swab and PCR positive for viral RNA. All patients were discharged by the monitoring service after reaching clinical stability and after performing two negative SARS-CoV-2 swabs within 24 hours of each other.

The following categories of patients were excluded: patients who died during the follow-up, following discharge; patients hospitalized at follow-up; patients under the 
age of 18; patients with psychiatric disorders; patients who refused to participate in the study; patients who could not be contacted.

Eligible patients were consecutively contacted and, after expressing consent to participate in the study, a semi-structured interview was administered by semistructured phone interview between February and March 2021 by trained medical staff of the COD19 operations center.

For some categories of symptoms, such as the occurrence of neurological and cognitive impairments, second- and third-level investigations including neurological and neurocognitive examination, neurophysiological and neuroradiological tests, were planned.

This study was approved by the Ethics Commission of the University of Milan, (Ethics Commission number: 126/20). Written informed consent was obtained from all participants.

\section{Semi-structured interview}

The most frequent symptoms reported in the literature were sought. A total of 37 items were surveyed and grouped in the following categories: respiratory disorders, fatigue and weakness, muscle and joint pain, movement impairments, neurological and cognitive impairments, sensory alterations, sleep disorders, and gastrointestinal symptoms.

We also explored whether complained symptoms were present prior to acute SARSCoV-2 infection and coded a symptom as present only if it was not reported prior to acute SARS-CoV-2 infection. 
All data regarding the acute phase of the disease was collected during monitoring by the COD19 operation center, either retrieved from electronic clinical records or by directly interviewing the patient in case of lack of information. Data included date of birth, sex, body mass index (BMI), smoking habits, symptoms at onset, admission to the hospital, type of hospitalization (in ward or in intensive care unit, ICU), medications taken during hospitalization and after hospital discharge (corticosteroids, antivirals, antibiotics, anticoagulants), and comorbidities (hypertension, diabetes, cardiovascular diseases, malignant tumors, chronic obstructive pulmonary disease, and chronic kidney disease).

Disease severity during the acute phase was graded in 7 levels according to Huang2: (1) discharged from the emergency room, asymptomatic or with mild symptoms; (2) discharged from the emergency room, with symptoms; (3) hospitalized, not requiring supplemental oxygen; (4) hospitalized, requiring supplemental oxygen; (5) hospitalized, requiring high-flow nasal cannula (HFNC), non-invasive mechanical ventilation (NIV), or both; (6) admitted to hospital requiring extracorporeal membrane oxygenation, invasive mechanical ventilation (IMV), or both; (7) death. Categories of BMI were defined as follows: underweight, BMI $<18.5 \mathrm{~kg} / \mathrm{m}^{2}$; normal weight, BMI 18.5-24.9 $\mathrm{kg} / \mathrm{m}^{2}$; overweight, BMI $25.0-29.9 \mathrm{~kg} / \mathrm{m}^{2}$; obese, BMI $\geq 30 \mathrm{~kg} / \mathrm{m}^{2}$.

\section{Statistical analysis}

Continuous variables are reported as median and IQR (25th, 75th percentile), while categorical variables are reported as count (fraction).

Participants were categorized into two groups according to Huang scale: 1-2 categories (not hospitalized with or without symptoms) and 3-6 categories (hospitalized, requiring or not oxygen or admitted to ICU). Statistical analyses were performed using the 
Wilcoxon rank sum test with continuity correction for continuous variables and with the Pearson's Chi-squared test and Fisher's exact test where appropriate for categorical variables.

Multivariable logistic regression models were used to describe the relationship between symptoms at follow-up (dichotomous, present/not present) and age (continuous), sex (dichotomous, female/male), and acute phase severity (dichotomous, scale 1-2/scale 36). Linearity between outcomes and age was not assumed by using restricted cubic spline, with quantile-define knots at 5 th, 35 th, 65 th, 95 th percentile. ${ }^{7}$

To present the results, prevalences were computed for the overall sample and stratified for each predictor, presented with the corresponding adjusted odds ratio (ORs) and 95\% confidence intervals (CI). Age groups were defined using non-boundary knots of the age spline.

Statistical analyses were performed in R 4.0.4.

\section{Role of the funding source}

The funders of the study had no role in study design, data collection, data analysis, data interpretation, or writing of the report. All authors had full access to all the data in the study and had final responsibility for the decision to submit for publication.

\section{Results}

A total of 717 patients was monitored between February 2020 and May 2020 and the follow-up study was conducted between February and March 2021. Of those, 303 were eligible and accepted to participate in the study and were enrolled (Figure 1). The non- 
confirmed diagnosis were patients monitored for symptoms compatible with COVID-19, but that were never confirmed by a positive molecular swab.

For the 303 included in the study, median (IQR) follow-up time was $12.2(11.5,12.6)$ months. Patients' characteristics are summarized in Table 1. While the overall sample is almost balanced in sex distribution, male patients were significantly more frequent in hospitalized patients ( $52 \%$ vs 35\%; $\mathrm{p}=0.05$ ). Median age was 53 (IQR: 42-63) years, but hospitalized patients were significantly older (median age: 57 vs. 45 years; $\mathrm{P}<0.001$ ). Most patients had a normal weight, with a median BMI of 24.9 (IQR: 22.9-28.0), with BMI categories similarly distributed in hospitalized and not hospitalized patients. While most patients never smoked (63\%), hospitalized patients had a higher prevalence of exsmokers (29\% vs. $13 \%$ ). The most prevalent comorbidities were hypertension (29\%), cardiovascular diseases (11\%), and diabetes (9.2\%), and their prevalence were significantly higher in hospitalized patients. Also, cerebrovascular disease was present only in hospitalized patients ( $5.8 \%$ vs $0 \%$; $\mathrm{p}=0.008$ ). Most of the non-hospitalized patients were still symptomatic, and most hospitalized patients required oxygen, either through nasal cannula or NIV. Hospitalized patients received more frequently treatments, including antibiotics, antivirals, corticosteroids, and low-molecular weight heparin (LMWH), than non-hospitalized during the acute phase of the disease.

Figure 2 shows nonparametric regression (locally estimated scatterplot smoothing, LOESS) estimates of the relationship between age at COVID-19 infection and the probability of presenting any symptoms at follow-up (panel A), stratified by sex (panel B), severity of the acute phase (panel C) or both (panel D). The probability increases with age, although females seem at higher risk in the range between 40-75 years of age. Moreover, non-hospitalized patients seem to have a lower risk than hospitalized, but 
the combined groups (panel D) highlight that the difference is mainly attributed to the category of male non-hospitalized patients.

Table 2, 3 and 4 show the prevalence of symptoms at follow-up in the overall sample and stratified by age groups, sex, or acute phase severity, respectively. Most patients (81\%) reported at least one symptom of those surveyed, and the most prevalent symptoms related to fatigue (52\%), pain (48\%) and sleep disorders (47\%). Sensory alterations were present in $28 \%$ of surveyed patients, but in most of these cases $(74 \%$ of those affected by sensory alterations or $20 \%$ of the overall sample) symptoms reported were either anosmia or dysgeusia. Higher prevalence was generally observed with increasing age, although the most relevant differences were observed when comparing young vs middle-aged adults. For example, when comparing the young age group (15-47 years) vs the middle-aged (47-58 years), significant differences include the proportion of those who complained of at least one symptom ( $92 \%$ vs $69 \%$; $\mathrm{p}<0.001)$, of fatigue and weakness ( $62 \%$ vs $36 \%$; $<<0.001)$, of muscular and joint pain ( $56 \%$ vs 33\%; $\mathrm{p}<0.001$ ), of sleep disorders ( $60 \%$ vs $33 \%$; $<<0.001)$, of respiratory disorders ( $45 \%$ vs $27 \%$; $=0.001$ ), of neurological and cognitive impairments (45\% vs $36 \% ; p=0.008$ ) and of gastrointestinal symptoms (15\% vs 9.4\%; $\mathrm{p}=0.03$ ). Sensory alterations were the only symptoms with a significantly lower frequency in older adults (aged between 58 and 90 years) compared to young (22\% vs 29\%; p=0.01). Significant differences between male and female include a higher prevalence of at least one symptom ( $84 \%$ vs $77 \%$; $p=0.02$ ), of fatigue and weakness ( $57 \%$ vs $46 \%$; $p=0.02$ ), of sleep disorders (51\% vs 41\%; $\mathrm{p}=0.03)$ and of sensory alterations (32\% vs $22 \%$; $\mathrm{p}=0.04$ ). Regarding the acute phase severity, all prevalence were higher in the more severe group, apart from the sensory alterations, but not with a significant difference. 
Even adjustment for age and gender did not reveal any impact from disease severity on risk of symptoms.

\section{Discussion}

This is, to our knowledge, the first cohort study which assess the health consequences of COVID-19 patients at one-year follow-up in either hospitalized and not hospitalized patients. Regardless of the severity of the acute phase, most patients (81\%) presented at least one symptom with the most prevalent being fatigue and weakness (52\%), muscle and joint pain (48\%), sleep disorders (47\%), neurological and cognitive impairment (36\%), and respiratory disorders (36\%).

We show that the likelihood of presenting symptoms generally increases with age, as reported by Huang and colleagues. Interestingly males showed lower prevalence for some symptoms. These findings are not limited to COVID-19, as similar data has been reported for the 2002-2004 severe acute respiratory syndrome (SARS) outbreak virus. Even in the case of SARS, one year after the disease, there was an impairment of the general health status. ${ }^{9}$ According to Ho-Bun Lam and colleagues, more than $40 \%$ of patients affected by SARS presented psychiatric illness and $40.3 \%$ reported chronic fatigue. ${ }^{10}$

In our sample, we found that $52 \%$ of patients complain of fatigue one year after the disease. Male sex seemingly represents a protective factor against this symptom. Huang and colleagues report a prevalence of fatigue of $63 \%$ six months after acute illness. ${ }^{2}$ Following the same time interval, Logue and colleagues report a prevalence of this symptom of $13.6 \% .^{3}$ To date, there is no pathophysiological explanation of the problem in literature, but some authors hypothesize that the causes are multifactorial. ${ }^{11}$ One of 
the possible causes could be to the prolonged bed stay of patients, with consequent loss of muscle trophism and tone mostly followed by an incomplete recovery. Our sample, however, included inpatients and outpatients who are unlikely to have been bedridden for long periods of time, and who still reported a high prevalence of fatigue (50\%).

Almost half of patients complained of arthromyalgia. While Huang and colleagues reported a joint pain rate of $9 \%$ and myalgia of $2 \%$ six months after the acute phase of the disease. ${ }^{2}$ This complaint is not limited to COVID-19, as also SARS-CoV-1 osteomuscular apparatus involvement has been described..$^{12}$ A possible explanation lies in the presence of particular receptors on the muscular tissue that are used by the SARS$\mathrm{CoV}-2$ to enter into the cell which include the angiotensin-converting enzyme 2 (ACE2) and the serine protease TMPRSS $2 .{ }^{13}$ Quarantine, social distancing and isolation can also partially explain the prevalence of arthromyalgia, as such measures inevitably led to reduction of physical activity with deconditioning possibly resulting in arthromyalgia. SARS-CoV-2-induced polyneuropathy may also partially explain the phenomenon. Several patients (47\%) complained also of sleep disorders, and the prevalence was lower among males. Tansey and colleagues report a similar prevalence (44\%) in survivors of SARS-CoV-1 infection one year after the acute event. ${ }^{14}$ This fraction is higher than the one detected in the general population, for example Chen et al. report a prevalence of sleep disorders in the general population of $4.7 \% \cdot{ }^{15} \mathrm{~A}$ multifactorial origin for sleep disorders is plausible, and social isolation and decreased physical activity are just some of the parameters that can, in addition to viral infection, may be taken into consideration for the explanation of the phenomenon.

Another symptom, reported by patients, is neurocognitive impairment, reported by $36 \%$ of our patients. Mazza and colleagues hypothesize that it can be secondary to a 
cytokine storm, since a prolonged exposure to systemic inflammation can predispose patients to persistent neurocognitive dysfunction. ${ }^{16}$

In our sample, $36 \%$ of patients complain of symptoms affecting the respiratory system. Dyspnea and increased respiratory rate are reported following light and moderate efforts. Huang and colleagues reported that by increasing the criticality level of the acute phase of the disease, the proportion of patients with lung diffusion impairment increased. ${ }^{2}$ This virus can damage the lungs in essentially three ways: acute respiratory distress syndrome (ARDS) with diffuse alveolar damage (DAD), diffuse thrombotic alveolar microvascular occlusion, and inflammatory mediator-associated airway inflammation. ${ }^{17}$ Ngai and colleagues showed the pulmonary effects of SARS-CoV-1 with a 2-year follow-up, highlighting a marked worsening in DL(CO), exercise capacity, resistance to exertion and health status. ${ }^{18}$

Almost one third of patients reported sensory alterations. The most common symptoms were loss or alteration of taste and smell, reported by $20 \%$ of the sample. Male sex, from our sample, seems to be a protective factor. These symptoms are very characteristic of SARS-CoV-2 infection, and since the first phase of the pandemic they have been considered as symptoms highly associated with the disease. Some studies report a prevalence rate of olfactory and gustatory alterations during the acute phase of $85.6 \%$ and $88.0 \%$ respectively. ${ }^{19}$ Causes are still unknown and only partially explained. In 2006, Hwang described a case of anosmia that persisted for two years after SARS-CoV-1 infection. ${ }^{20}$ Huang and colleagues report the prevalence of changes in smell of $11 \%$ and of taste changes of $7 \%$ at a follow-up of 6 months. ${ }^{2}$

Eighteen percent of the sample analyzed complained of an impairment in movement which was not influenced by disease severity and gender. This fraction was higher than 
the one reported by Huang which was 7\%. This symptom can have different causes, including an impairment of peripheral nervous system which can determine less coordination in walking or be due to fatigue and a lower respiratory threshold.

Fothui and colleagues describe the neurobiology of SARS-CoV-2, hypothesizing that the damage to the peripheral nervous system has a multifactorial cause deriving from both a virus-specific neurotropism and a cytokine storm following the binding of SARS-CoV-2 to the receptor ACE2. ${ }^{21}$ Cases of Guillan-Barrè associated with Covid-19 are also reported in the literature. A review by Trujillo Gittermann and colleagues reports a strong association between these two pathologies, without however confirming a causeeffect relationship. ${ }^{22}$

Our sample complained of gastrointestinal disorders in $12 \%$ of cases, including anorexia or diarrhea. Degeneration, necrosis, shedding of the gastrointestinal mucosa of varying degrees and ACE2 were found histologically in one patient who died of severe COVID-19, suggesting that the damage to the intestinal mucosa results from the direct action of the virus. ${ }^{23}$ Huang and colleagues showed a prevalence of anorexia, diarrhea and vomiting of $13 \%$, very close to our results. ${ }^{2}$

There are other less frequent symptoms reported by patients which are more difficult to explain. A proportion of $5.6 \%$ of patients reported episodes of alopecia, which often regresses spontaneously, but sometimes requires topical or systemic steroid therapy. Huang and colleagues reported a hair loss rate of $22 \%$ six months after the acute phase of the disease,,$^{2}$ while $67 \%$ of patients evaluated by Tansey and colleagues reported selfresolving alopecia, usually within 3 months from SARS-CoV-1 infection. ${ }^{14}$ From the recent literature it would be caused either by a greater androgenetic sensitivity or by 
telogen effluvium. ${ }^{24,25}$ Visual impairment, present in 3.9\% of patients, is difficult to explain by a pathophysiological point of view.

The variety of symptoms that involve different organs, the complexity of the presentation and the clinical course, and the unpredictability of the evolution, lead to the definition of the long COVID syndrome. It is important to report that we did not find any association between the course of the disease in the acute phase and the symptom occurrence at one-year follow-up; for this reason, close attention must be paid to the population affected by COVID-19 irrespective of the fact that they have been hospitalized or not. A particular care should be given to individuals who had COVID-19 infection in the range of age 47-58 years, and to women more than men, since they reported a higher prevalence of symptoms. The follow-up of COVID-19 patients need to be managed using a multidisciplinary approach involving different specialties, as most patients seems to be affected by at least one symptom which ranges from respiratory involvement to neurological complications.

However, there are several limitations of the study. The main limitation is the lack of a control group, that prevents a causal association between COVID-19 infection and symptoms at follow-up. Only $42.3 \%$ of patients originally monitored were included in this follow-up study. Main reasons of exclusion were an unclear diagnosis $(32.2 \%)$ and the impossibility to reach these patients by phone (16\%), while very few refused to participate $(0.6 \%)$, and reported deaths were low $(0.3 \%)$. The study relies on a semistructured phone-interview which was administered by trained staff personnel 1-year after acute disease, bringing the risk of recall bias. Second- and third-level investigations are ongoing, but we cannot exclude that some symptoms reported by patients have subjective more than objective origin. We did not record if a symptom 
present before the acute phase worsen after the infection, as such our result may underestimate COVID-19 health consequences. Also, variants of the virus have not been systematically assessed, and it is possible the different variant may have been associated with a different set of long term symptoms.

In conclusion, we highlighted in a sample of confirmed COVID-19 diagnosis inclusive of patients with a less severe acute phase that clinical complications are still present at one-year follow-up. Main findings are that symptoms are still present at 12-month follow-up with a prevalence similar to shorter follow-up and that they are present irrespective of COVID-19 severity. These data will be useful to promote health policy measures such as long-term surveillance programs and facilities dedicated to the management of patients affected by long COVID syndrome. 


\section{Acknowledgment}

\section{Funding}

This work was supported by Fondazione Invernizzi and Regional Operational Programme (ERDF ROP) 2014-2020

\section{Contributors}

MDML, AF and GVZ conceived and designed the study and took responsibility for the integrity of the data and the accuracy of the data analysis. All authors had full access to all the data of the study. MDML and AF drafted the manuscript. AF did statistical analysis, and all authors critically revised the manuscript for important intellectual content and gave final approval for the version to be published. MDML and AF completed the follow up work and collected the data. All authors agree to be accountable for all aspects of the work in ensuring that question related to the accuracy or integrity of any part of the work are appropriately investigated and resolved.

\section{Potential Conflicts of Interest}

We declare no conflict of interest. 


\section{References}

1 World Health Organization. COVID-19 Weekly Epidemiological Update 22. World Health Organization 2020; : 1-3.

2 Huang C, Huang L, Wang Y, et al. 6-month consequences of COVID-19 in patients discharged from hospital: a cohort study. The Lancet 2021. DOI:10.1016/S01406736(20)32656-8.

3 Logue JK, Franko NM, McCulloch DJ, et al. Sequelae in Adults at 6 Months After COVID-19 Infection. JAMA Network Open 2021; 4: e210830.

4 Graham EL, Clark JR, Orban ZS, et al. Persistent neurologic symptoms and cognitive dysfunction in non-hospitalized Covid-19 'long haulers'. Annals of Clinical and Translational Neurology 2021; : acn3.51350.

5 Lilleri D, Zavaglio F, Gabanti E, Gerna G, Arbustini E. Analysis of the SARS-CoV-2 epidemic in Italy: The role of local and interventional factors in the control of the epidemic. PLoS ONE 2020; 15: 1-2.

6 Zuccotti GV, Bertoli S, Foppiani A, Verduci E, Battezzati A. Cod19 and cod20: An Italian experience of active home surveillance in covid-19 patients. International Journal of Environmental Research and Public Health 2020; 17: 1-3.

7 Harrell, FE. Regression Modeling Strategies. Cham: Springer International Publishing, 2015 DOI:10.1007/978-3-319-19425-7.

8 R Core Team. R: A language and environment for statistical computing. Vienna, Austria: R Foundation for Statistical Computing, 2021 https://www.R-project.org/.

9 Hui DSC, Wong KT, Antonio GE, Tong M, Chan DP, Sung JJY. Long-term sequelae of SARS: physical, neuropsychiatric, and quality-of-life assessment. Hong Kong medical journal = Xianggang yi xue za zhi 2009; 15 Suppl 8: 21-3. 

severe acute respiratory syndrome survivors: long-term follow-up. Archives of internal medicine 2009; 169: 2142-7.

11 Rudroff T, Fietsam AC, Deters JR, Bryant AD, Kamholz J. Post-COVID-19 Fatigue: Potential Contributing Factors. Brain sciences 2020; 10. DOI:10.3390/brainsci10121012. 12 Moldofsky H, Patcai J. Chronic widespread musculoskeletal pain, fatigue, depression and disordered sleep in chronic post-SARS syndrome; a case-controlled study. BMC neurology 2011; 11: 37.

13 Disser NP, De Micheli AJ, Schonk MM, et al. Musculoskeletal Consequences of COVID-19. The Journal of bone and joint surgery American volume 2020; 102: 1197-204. 14 Catherine M. Tansey, MSc; Marie Louie, MD; Mark Loeb, MD; Wayne L. Gold, MD; Matthew P. Muller, MD; JoAnne de Jager, BSc(N); Jill I. Cameron, PhD; George Tomlinson, PhD; Tony Mazzulli, MD; Sharon L. Walmsley, MD; Anita R. Rachlis, MD; Barbara D. Mederski, M. One-year outcomes and health care utilization in survivors of severe acute respiratory syndrome (SARS). Nederlands Tijdschrift voor Geneeskunde 2007; 151: 2865.

15 Chen Y-C, Lin C-Y, Strong C, et al. Sleep disturbances at the time of a new diagnosis: a comparative study of human immunodeficiency virus patients, cancer patients, and general population controls. Sleep Medicine 2017; 36: 38-43.

16 Gennaro MM, Mariagrazia P, De Lorenzo R, et al. Persistent psychopathology and neurocognitive impairment in COVID-19 survivors: effect of inflammatory biomarkers at three-month follow-up. Brain, behavior, and immunity 2021; published online Feb. DOI:10.1016/j.bbi.2021.02.021. 
Sequelae of COVID-19. Medical science monitor: international medical journal of experimental and clinical research 2020; 26: e928996.

18 Ngai JC, Ko FW, Ng SS, To K-W, Tong M, Hui DS. The long-term impact of severe acute respiratory syndrome on pulmonary function, exercise capacity and health status. Respirology (Carlton, Vic) 2010; 15: 543-50.

19 Lechien JR, Chiesa-Estomba CM, De Siati DR, et al. Olfactory and gustatory dysfunctions as a clinical presentation of mild-to-moderate forms of the coronavirus disease (COVID-19): a multicenter European study. European Archives of Oto-RhinoLaryngology 2020; 277: 2251-61.

20 Hwang C-S. Olfactory neuropathy in severe acute respiratory syndrome: report of A case. Acta neurologica Taiwanica 2006; 15: 26-8.

21 Fotuhi M, Mian A, Meysami S, Raji CA. Neurobiology of COVID-19. Journal of Alzheimer's disease: JAD 2020; 76: 3-19.

22 Trujillo Gittermann LM, Valenzuela Feris SN, von Oetinger Giacoman A. Relation between COVID-19 and Guillain-Barré syndrome in adults. Systematic review. Neurologia (Barcelona, Spain) 2020; 35: 646-54.

23 Tian Y, Rong L, Nian W, He Y. Review article: gastrointestinal features in COVID19 and the possibility of faecal transmission. 2020. DOI:10.1111/apt.15731.

24 Wambier CG, Vaño-Galván S, McCoy J, et al. Androgenetic alopecia present in the majority of patients hospitalized with COVID-19: The "Gabrin sign". Journal of the American Academy of Dermatology 2020; 83: 680-2.

25 Rivetti N, Barruscotti S. Management of telogen effluvium during the COVID-19 emergency: Psychological implications. Dermatologic therapy 2020; 33: e13648. 
Table 1. Patient characteristics during the acute phase

\begin{tabular}{|c|c|c|c|c|}
\hline & \multirow[b]{2}{*}{$\begin{array}{l}\text { Overall, } \\
\mathrm{N}=303^{1}\end{array}$} & \multicolumn{2}{|c|}{ Acute phase severity } & \multirow[b]{2}{*}{ p-value ${ }^{2}$} \\
\hline & & $\begin{array}{l}\text { Scale 1-2: Not } \\
\text { hospitalized, } \\
\quad N=114^{1}\end{array}$ & $\begin{array}{c}\text { Scale 3-6: Hospitalized, N } \\
=189^{1}\end{array}$ & \\
\hline Sex & & & & 0.005 \\
\hline Female & $165(54 \%)$ & $74(65 \%)$ & $91(48 \%)$ & ) \\
\hline Male & $138(46 \%)$ & $40(35 \%)$ & $98(52 \%)$ & \\
\hline Age (years) & $53(42,63)$ & $45(38,54)$ & $57(47,68)$ & $<0.001$ \\
\hline $\begin{array}{l}\text { Body mass index } \\
\left(\mathrm{kg} / \mathrm{m}^{2}\right)\end{array}$ & $24.9(22.9,28.0)$ & $24.5(21.8,27.5)$ & $25.2(23.3,28.2)$ & 0.033 \\
\hline $\begin{array}{l}\text { Body mass index } \\
\text { categories }\end{array}$ & & & & 0.4 \\
\hline Underweight & $9(3.0 \%)$ & $4(3.5 \%)$ & $5(2.6 \%)$ & \\
\hline Normal weight & $154(51 \%)$ & $64(56 \%)$ & $90(48 \%)$ & \\
\hline Overweight & $91(30 \%)$ & $31(27 \%)$ & $60(32 \%)$ & \\
\hline Obese & $49(16 \%)$ & $15(13 \%)$ & $34(18 \%)$ & \\
\hline Smoking habits & & & & $<0.001$ \\
\hline Never smoked & $192(63 \%)$ & $75(66 \%)$ & $117(62 \%)$ & \\
\hline Ex-smoker & $70(23 \%)$ & $15(13 \%)$ & $55(29 \%)$ & \\
\hline Smoker & $41(14 \%)$ & $24(21 \%)$ & $17(9.0 \%)$ & \\
\hline
\end{tabular}

\section{Comorbidities}




\begin{tabular}{|c|c|c|c|c|}
\hline Cardiovascular disease & $32(11 \%)$ & $5(4.4 \%)$ & 27 (14\%) & 0.007 \\
\hline Diabetes & $28(9.2 \%)$ & $4(3.5 \%)$ & $24(13 \%)$ & 0.007 \\
\hline Malignant tumors & $18(5.9 \%)$ & $6(5.3 \%)$ & $12(6.3 \%)$ & 0.7 \\
\hline $\begin{array}{l}\text { Chronic obstructive } \\
\text { pulmonary disease }\end{array}$ & $17(5.6 \%)$ & $6(5.3 \%)$ & $11(5.8 \%)$ & 0.8 \\
\hline $\begin{array}{l}\text { Cerebrovascular } \\
\text { disease }\end{array}$ & $11(3.6 \%)$ & $0(0 \%)$ & $11(5.8 \%)$ & 0.008 \\
\hline Chronic kidney disease & $4(1.3 \%)$ & $0(0 \%)$ & & 0.3 \\
\hline \multicolumn{5}{|l|}{ Acute phase severity } \\
\hline $\begin{array}{l}\text { Scale 1: Not } \\
\text { hospitalized, } \\
\text { asymptomatic }\end{array}$ & $11(3.6 \%)$ & $11(9.6 \%)$ & $0(0 \%)$ & $<0.001$ \\
\hline $\begin{array}{l}\text { Scale 2: Not } \\
\text { hospitalized, } \\
\text { symptomatic }\end{array}$ & $103(34 \%)$ & $103(90 \%)$ & $0(0 \%)$ & $<0.001$ \\
\hline $\begin{array}{l}\text { Scale 3: Hospitalized, } \\
\text { not requiring oxygen }\end{array}$ & $43(14 \%)$ & $0(0 \%)$ & $43(23 \%)$ & $<0.001$ \\
\hline $\begin{array}{l}\text { Scale 4: Hospitalized, } \\
\text { requiring oxygen (nasal } \\
\text { cannula) }\end{array}$ & 67 (22\%) & $0(0 \%)$ & $67(35 \%)$ & $<0.001$ \\
\hline $\begin{array}{l}\text { Scale } 5 \text { : Hospitalized, } \\
\text { requiring oxygen (NIV) }\end{array}$ & $71(23 \%)$ & $0(0 \%)$ & $71(38 \%)$ & $<0.001$ \\
\hline $\begin{array}{l}\text { Scale 6: Hospitalized, } \\
\text { ICU }\end{array}$ & $8(2.6 \%)$ & $0(0 \%)$ & $8(4.2 \%)$ & 0.027 \\
\hline
\end{tabular}

\section{Treatment during the acute phase}

\begin{tabular}{|c|c|c|c|c|}
\hline Antivirals & 187 (62\%) & $31(27 \%)$ & $156(83 \%)$ & $<0.001$ \\
\hline Antibiotics & 134 (44\%) & $29(25 \%)$ & $105(56 \%)$ & $<0.001$ \\
\hline LMWH & $94(31 \%)$ & 17 (15\%) & 77 (41\%) & $<0.001$ \\
\hline
\end{tabular}


Steroids

$14(4.6 \%)$

$5(4.4 \%)$

$9(4.8 \%)$

${ }^{1} \mathrm{n}(\%)$; Median (IQR)

${ }^{2}$ Pearson's Chi-squared test; Wilcoxon rank sum test; Fisher's exact test

Abbreviations: low-molecular weight heparin (LMWH), non-invasive mechanical ventilation (NIV) 
Table 2. Symptoms at follow-up stratified by age groups

\begin{tabular}{|c|c|c|c|c|c|c|c|}
\hline & \multirow{2}{*}{ Overall, $N=303$} & \multicolumn{3}{|c|}{ Age group (range in years) } & \multicolumn{3}{|c|}{ Adjusted log(OR) $(95 \% \mathrm{Cl}) \mathrm{p}$-value } \\
\hline & & $18-47$ & 17-58, $N=91$ & $58-90, N=106$ & $18-47$ years & $47-58$ years & $58-90$ years \\
\hline $\begin{array}{l}\text { Any one of the following } \\
\text { symptoms }\end{array}$ & $244(81 \%)$ & & $84(92 \%)$ & $87(82 \%)$ & $0.63(-0.57,1.85) 0.302$ & $3.85(2.32,5.49)<0.001$ & $0.17(-0.80,1.22) 0.737$ \\
\hline Fatigue and weakness & $158(52 \%)$ & $38(36 \%)$ & $56(62 \%)$ & $64(60 \%)$ & $1.52(0.59,2.47) 0.001$ & $3.30(1.72,5.12)<0.001$ & $0.78(0.02,1.55) 0.044$ \\
\hline Muscle and joint pain & $144(48 \%)$ & $35(33 \%)$ & $51(56 \%)$ & $58(55 \%)$ & $1.01(0.08,1.95) 0.033$ & $4.12(2.31,6.28)<0.001$ & $0.74(-0.02,1.52) 0.057$ \\
\hline Sleep disorders & $141(47 \%)$ & $35(33 \%)$ & $55(60 \%)$ & $51(48 \%)$ & $1.21(0.28,2.15) \mathbf{0 . 0 1 1}$ & $3.28(1.60,5.23)<0.001$ & $0.19(-0.58,0.96) 0.626$ \\
\hline Respiratory disorders & $110(36 \%)$ & $29(27 \%)$ & $41(45 \%)$ & $40(38 \%)$ & $0.39(-0.56,1.34) 0.426$ & $3.34(1.50,5.53) 0.001$ & $0.38(-0.40,1.16) 0.341$ \\
\hline $\begin{array}{l}\text { Neurological and } \\
\text { cognitive impairments }\end{array}$ & $110(36 \%)$ & $31(29 \%)$ & $41(45 \%)$ & $38(36 \%)$ & $0.65(-0.29,1.60) 0.179$ & $2.41(0.74,4.36) 0.008$ & $0.15(-0.64,0.93) 0.704$ \\
\hline Sensory alterations & $84(28 \%)$ & $31(29 \%)$ & $30(33 \%)$ & $23(22 \%)$ & $0.69(-0.37,1.76) 0.205$ & $0.04(-1.55,1.76) 0.962$ & $-1.35(-2.56-0.33) \mathbf{0 . 0 1 6}$ \\
\hline Movement impairments & $54(18 \%)$ & $16(15 \%)$ & $18(20 \%)$ & 20 (19\%) & $0.46(-0.73,1.66) 0.454$ & $2.08(-0.06,4.80) 0.087$ & $-0.06(-1.14,0.93) 0.907$ \\
\hline $\begin{array}{l}\text { Gastrointestinal } \\
\text { symptoms }\end{array}$ & $35(12 \%)$ & $10(9.4 \%)$ & $14(15 \%)$ & $11(10 \%)$ & $0.58(-0.97,2.28) 0.477$ & $5.11(1.30,10.71) 0.030$ & $0.10(-1.32,1.49) 0.882$ \\
\hline
\end{tabular}


Table 3. Symptoms at follow-up stratified by sex

\begin{tabular}{|c|c|c|c|c|c|c|}
\hline & \multicolumn{3}{|c|}{ Sex } & \multirow{2}{*}{$\begin{array}{c}\text { Adjusted } \\
\log (\text { OR) }\end{array}$} & \multirow{2}{*}{$95 \% \mathrm{Cl}$} & \multirow{2}{*}{ p-value } \\
\hline & & $\begin{array}{c}\text { Female } \\
\text { (reference) }\end{array}$ & Male & & & \\
\hline $\begin{array}{l}\text { Any one of the } \\
\text { following symptoms }\end{array}$ & $244(81 \%)$ & $138(84 \%)$ & $106(77 \%)$ & -0.76 & $-1.41,-0.13$ & 0.020 \\
\hline $\begin{array}{l}\text { Fatigue and } \\
\text { weakness }\end{array}$ & 158 (52\%) & $94(57 \%)$ & $64(46 \%)$ & -0.57 & $-1.06,-0.09$ & 0.022 \\
\hline Muscle and joint pain & $144(48 \%)$ & $83(50 \%)$ & $61(44 \%)$ & -0.40 & $-0.89,0.08$ & 0.101 \\
\hline Sleep disorders & $141(47 \%)$ & $84(51 \%)$ & $57(41 \%)$ & -0.52 & $-1.01,-0.04$ & 0.034 \\
\hline Respiratory disorders & $110(36 \%)$ & $63(38 \%)$ & 47 (34\%) & -0.26 & $-0.75,0.23$ & 0.295 \\
\hline $\begin{array}{l}\text { Neurological and } \\
\text { cognitive } \\
\text { impairments }\end{array}$ & $110(36 \%)$ & $66(40 \%)$ & $44(32 \%)$ & -0.46 & $-0.95,0.03$ & 0.069 \\
\hline Sensory alterations & $84(28 \%)$ & $53(32 \%)$ & 31 (22\%) & -0.55 & $-1.09,-0.02$ & 0.044 \\
\hline $\begin{array}{l}\text { Movement } \\
\text { impairments }\end{array}$ & 54 (18\%) & $33(20 \%)$ & 21 (15\%) & -0.39 & $-1.01,0.22$ & 0.218 \\
\hline $\begin{array}{l}\text { Gastrointestinal } \\
\text { symptoms }\end{array}$ & 10) & $21(13 \%)$ & $14(10 \%)$ & -0.34 & $-1.09,0.39$ & 0.363 \\
\hline
\end{tabular}


Table 4. Symptoms at follow-up stratified by acute phase severity

\begin{tabular}{|c|c|c|c|c|c|c|}
\hline \multicolumn{7}{|c|}{ Acute phase severity } \\
\hline & Overall & $\begin{array}{l}\text { Scale 1-2: Not } \\
\text { hospitalized } \\
\text { (reference) }\end{array}$ & $\begin{array}{c}\text { Scale 3-6: } \\
\text { Hospitalized }\end{array}$ & $\begin{array}{l}\text { Adjusted } \\
\log (O R)\end{array}$ & $95 \% \mathrm{Cl}$ & $p$-value \\
\hline $\begin{array}{l}\text { Any one of the } \\
\text { following symptoms }\end{array}$ & $244(81 \%)$ & 87 (76\%) & 157 (83\%) & 0.379 & $-0.30,1.06$ & 0.272 \\
\hline $\begin{array}{l}\text { Fatigue and } \\
\text { weakness }\end{array}$ & $158(52 \%)$ & $57(50 \%)$ & $101(53 \%)$ & -0.069 & $-0.61,0.46$ & 0.801 \\
\hline Muscle and joint pain & $144(48 \%)$ & 48 (42\%) & $96(51 \%)$ & 0.178 & $-0.35,0.71$ & 0.510 \\
\hline Sleep disorders & $141(47 \%)$ & $52(46 \%)$ & $89(47 \%)$ & -0.016 & $-0.55,0.51$ & 0.953 \\
\hline Respiratory disorders & $110(36 \%)$ & $40(35 \%)$ & $70(37 \%$ & -0.009 & $-0.55,0.53$ & 0.975 \\
\hline $\begin{array}{l}\text { Neurological and } \\
\text { cognitive impairments }\end{array}$ & $110(36 \%)$ & $39(34 \%)$ & $71(38 \%)$ & 0.121 & $-0.41,0.66$ & 0.657 \\
\hline Sensory alterations & $84(28 \%)$ & $35(31 \%)$ & $49(26 \%)$ & -0.015 & $-0.57,0.55$ & 0.959 \\
\hline $\begin{array}{l}\text { Movement } \\
\text { impairments }\end{array}$ & $54(18 \%)$ & $21(18 \%)$ & $33(17 \%)$ & -0.047 & $-0.70,0.62$ & 0.887 \\
\hline $\begin{array}{l}\text { Gastrointestinal } \\
\text { symptoms }\end{array}$ & $35(12 \%)$ & $13(11 \%)$ & $22(12 \%)$ & 0.034 & $-0.74,0.84$ & 0.932 \\
\hline
\end{tabular}




\section{Figure Legends}

Figure 1. Flow chart of patients discharged from COD19 service and participating to the study.

Figure 2. Relationship between age and probability of presenting any symptoms at follow-up (locally estimated scatterplot smoothing, LOESS), with tick marks representing age distribution. Panel A: no strata. Panel B: stratified by sex. Panel C: stratified by severity of the acute phase. Panel D: stratified by sex and severity of the acute phase. 
Assessed for eligibility $(n=717)$

Excluded $(n=414)$

- No confirmed diagnosis $(n=231)$

- Could not be contacted $(n=115)$

- Not meeting inclusion criteria $(n=64)$

- Age $(n=55)$

- Psychiatric disorder $(n=5)$

- Hospitalized at follow-up $(n=2)$

- Deceased $(n=2)$

- Declined to participate $(n=4)$

Analysed $(n=303)$ 
Figure 2

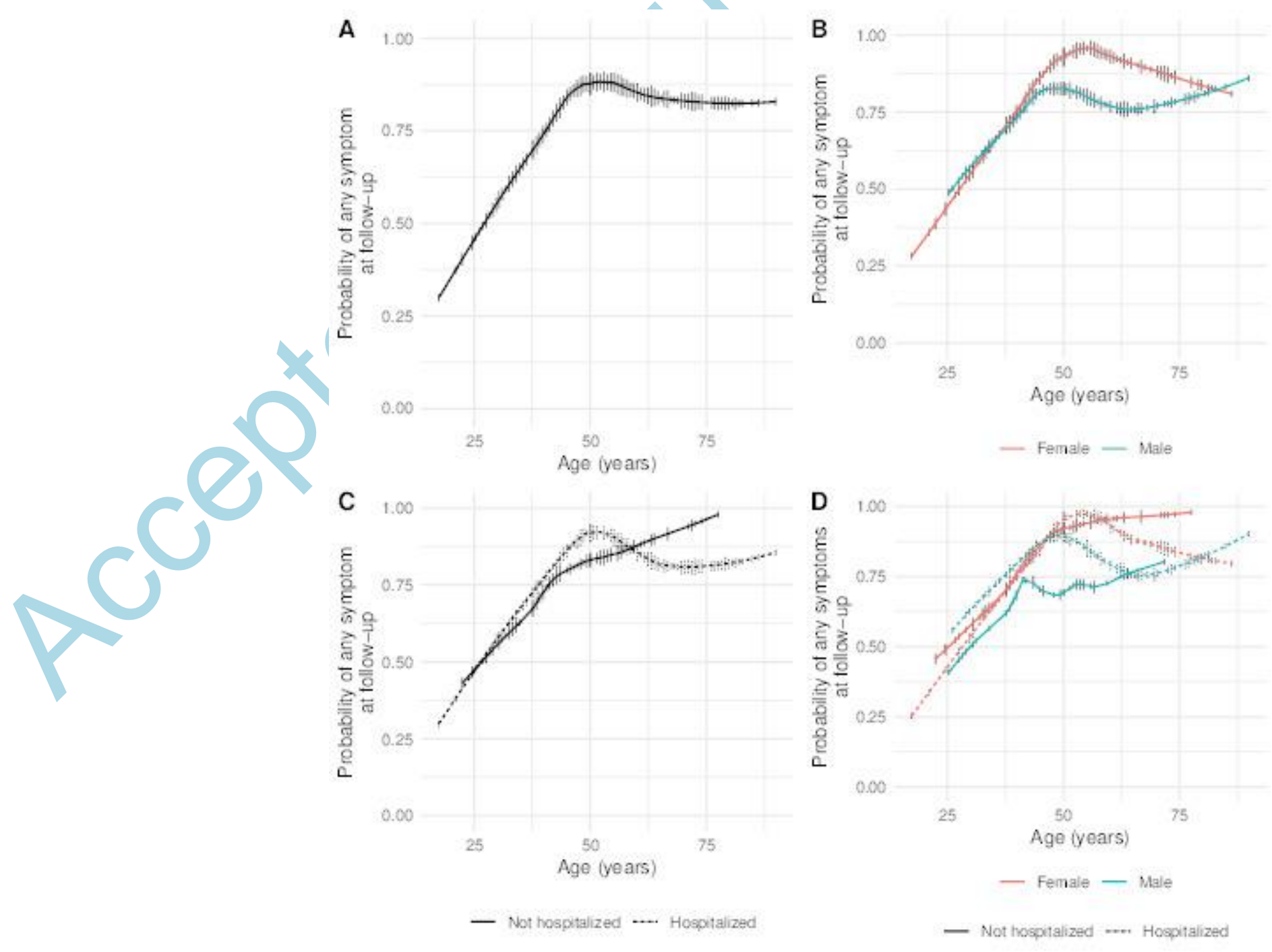

